\title{
Outcome of intensive outpatient rehabilitation and bracing in an adult patient with Scheuermann's disease evaluated by radiologic imaging - a case report
}

Hagit Berdishevsky

From 12th International Conference on Conservative Management of Spinal Deformities - SOSORT 2015 Annual Meeting Katowice, Poland. 7-9 May 2015

\begin{abstract}
Background: No studies examine the efficacy of intensive specific physical therapy (PT) exercises along with brace for the adult with Scheuermann's kyphosis (SK).

The aim of this study was to examine the effects of intensive PT based on the Barcelona Scoliosis Physical Therapy School (BSPTS) and SpinoMed brace on a 76-year-old female with SK.

Case Description: A 76-year-old female, diagnosed with SK as an adolescent, presented in October 2014 with thoracic hyperkyphosis T1 to T12 Cobb angle of $85^{\circ}$ and lumbar hyper lordosis L1 to L5 Cobb angle of $70^{\circ}$. Lumbar scoliosis T12-L5 with $21^{\circ} \mathrm{Cobb}$ and vertebral rotation 2. Trunk translation in the sagittal plan was $4.5 \mathrm{~cm}$. Intermittent low back pain 6/10 at worst. Quality-of-life score was 3.8 (SRS 22 questionnaire).

Method: The PT regimen included one-hour Schroth exercise sessions three times per week for 6 months. In addition, a home exercise program (HEP) was recommended. Patient also wore a SpinoMed brace for $2 \mathrm{~h}$ per day. All tests and measurements were recorded before and after treatment.

Results: After a six-month treatment period the kyphosis Cobb angle was reduced to $70^{\circ}$ and the lordosis Cobb angle improved to $57^{\circ}$. A recent $\mathrm{x}$-ray (October 2015) showed another improvement in the sagittal plane with thoracic kyphosis measuring $64^{\circ}$ and lumbar lordosis $55^{\circ}$. Lumbar curvature decreased to $12^{\circ}$ and vertebral rotation to 1. The quality-of-life score showed improvement with a score of 4.5 on the SRS 22. Pain score diminished to 2. Trunk deviation improved by $2.2 \mathrm{~cm}$.
\end{abstract}

Conclusion: These findings suggest that intensive and specific PT and bracing were successful for the treatment of this adult patient with SK. 


\section{Background}

Scheuermann's disease (SD), or Scheuermann's kyphosis (SK), is a condition developed in the early adolescence in which the normal round-back in the upper spine (called a kyphosis) is increased [1]. This condition has been reported to occur in 0.4 to $8.3 \%$ [OR IS IT $0.8 \%$ ??] of the general adolescent population, with an equal distribution between sexes. However, the prevalence and incidence of hyperkyphosis in older adults increases and varies from approximately 20 to $40 \%$ [2]. Most people with SK have an increased round-back (e.g. a hunch back or hump back) but no pain [3]. Nonetheless, untreated kyphosis in the growing child may lead to progressive deformity of the spine and back pain [4].

Several studies report that adolescents with SK who have undergone PT showed improvement in Cobb angle and respiration [5-10]. However, no studies have examined the efficacy of intensive outpatient specific physical therapy exercises for kyphosis along with brace for the management of adults with SK.

The aim of this study was to observe the effect of a six-month intensive physical therapy program based on the BSPTS method - using the Schroth principles and the SpinoMed brace - on the Cobb angle, pain, quality of life, core strength and back strength of a 76-year-old woman with SK.

\section{Case Presentation}

At the time of evaluation, the patient was a 76-year-old woman who was diagnosed with SK when she was an adolescent. Her thoracic kyphosis Cobb angle was measured initially ( $\mathrm{T} 1$ to $\mathrm{T} 12$ ) at $85^{\circ}$ with at least three wedged vertebrae from T5 to T11 (see Fig. 1). Her lumbar lordosis (L1 to L5) was measured with a Cobb angle of $70^{\circ}$ (see Fig. 1). Trunk translation in the sagittal plane was $4.5 \mathrm{~cm}$ measured T1 to base of S1. The patient also had lumbar scoliosis with convexity on the left side measured at Cobb $21^{\circ}$ with vertebral rotation grade 2 according to the Nash and Moe scale [11]. She experienced intermittent low back pain measured at 6/10 at worst using the Visual Analog Scale (VAS). Quality-oflife score was 3.8 using the SRS 22 questionnaire. Core stability and erectors spine strength was graded as good minus (-4/5) using Manual Muscle Testing appropriate tests.

\section{Method}

The PT regimen included one-hour BSPTS/Schroth method exercise sessions that consisted of 1:1 supervised treatments at the patient's home, three times per week for 6 months, focusing on using the five BSPTS Principles of Corrections (POC) [12] for sagittal plane deformities:

1. Trunk Elongation - and expansion throughout the trunk to de-collapse the spine.

2. Symmetrical Sagittal Straightening - More specific tension and expansion; in contrast to treatment for scoliosis and other sagittal plane deformities, the correction during this phase is symmetrical for SK, meaning that exercises are identical for both sides of the trunk (right and left):

a. Thoracic expansion bilaterally in the frontal plane and in a posterior to anterior (PA) direction in the sagittal to reduce the hyperkyphosis thoracic;

b. Lumbar expansion bilaterally as well in the frontal plane and in an anterior to posterior (AP) direction in the sagittal plan to reduce the hyperlordotic low back.

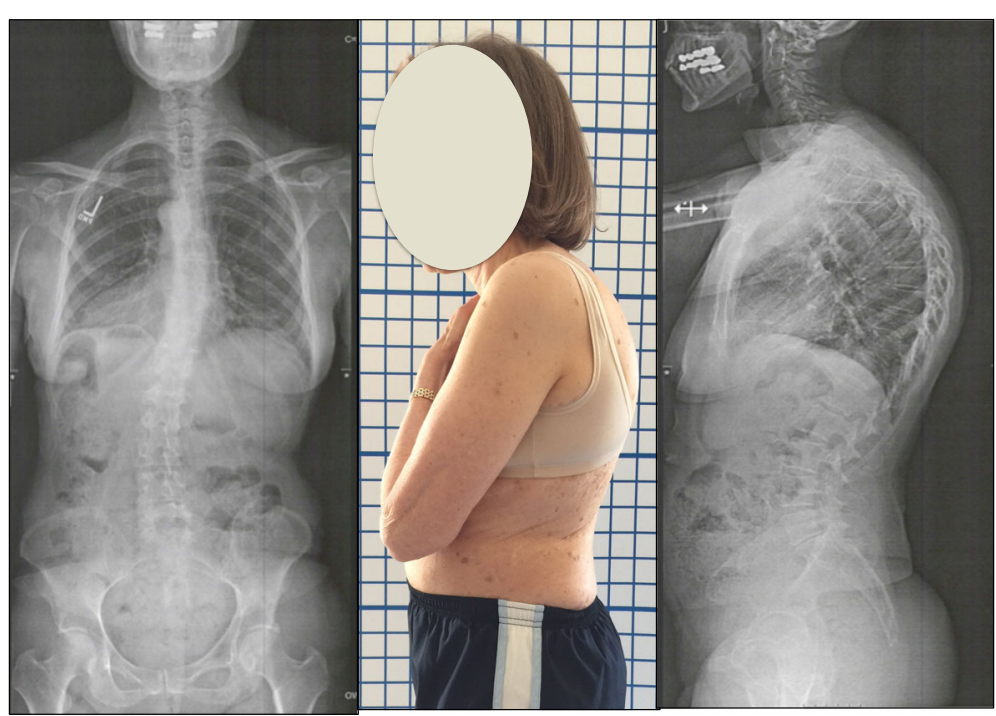

Fig. 1 X-ray and clinical picture at evaluation of patient (March 2014): Thoracic kyphosis measured at $86^{\circ}$ and lumbar lordosis at $70^{\circ}$ 


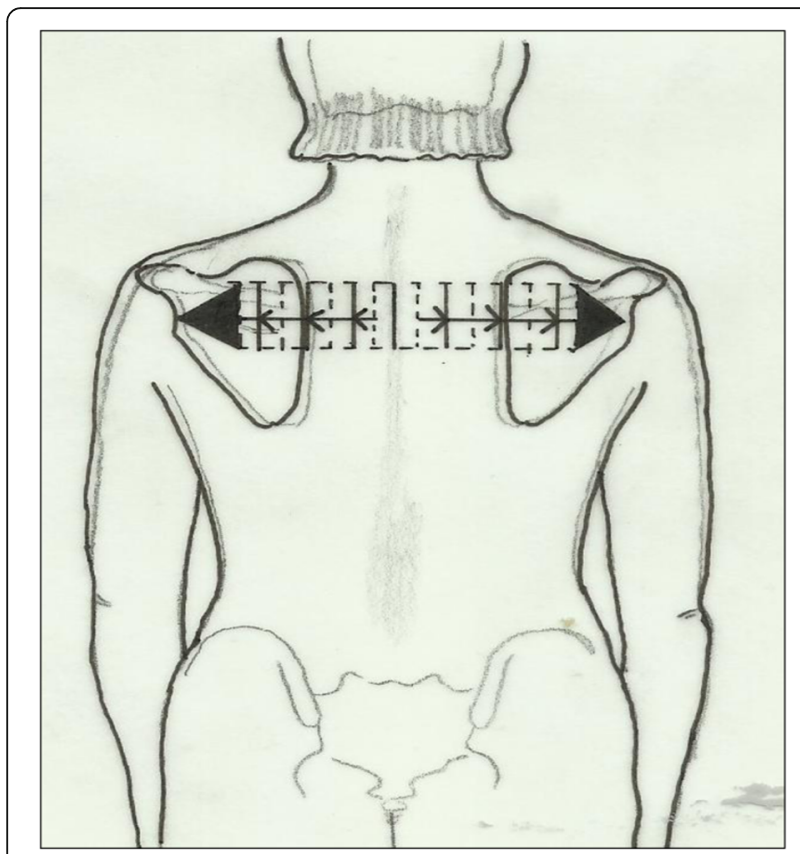

Fig. 2 Shoulder Traction - A subject with a hyper-kyphotic morphology will pay more attention to the transversal expansion. Transversal expansion in the proximal thoracic region is an essential part of the correction to facilitate self-elongation (or axial expansion) and can facilitate reduction in the sagittal plane (a plane of maximum deformity in Scheuermann's kyphosis). Copyright to Dr. Rigo Manuel
3. Shoulder Traction (see Fig. 2) - Isometric tension that is performed bilaterally starting at the shoulder region enhances the frontal plane correction/ expansion of the thorax.

4. Corrective Breathing - Inhaling while maintaining all of the correction principles allows the subject to feel an increased expansion in his/her initially collapsed regions. This is done simultaneously on the right and left sides of the patient with the goal of expanding in a back-to-front direction in the thorax as well as laterally.

5. Muscle Activation by Increasing Tension Isometric tension to achieve the best possible correction and muscle balance. From one side it stabilizes the correction and from the other side it increases the proprioceptive corrective input so that it helps to integrate the 'corrected body schema' in the brain.

In addition, a home exercise program, which consisted of 60-minute sessions on a daily basis, was recommended (see Fig. 3 for example of the patient's home exercises). The patient also wore a SpinoMed brace that was recommended by the therapist, and was instructed to wear the brace while walking for a maximum $2 \mathrm{~h}$ each day. The SpinoMed brace is a spinal orthosis that was
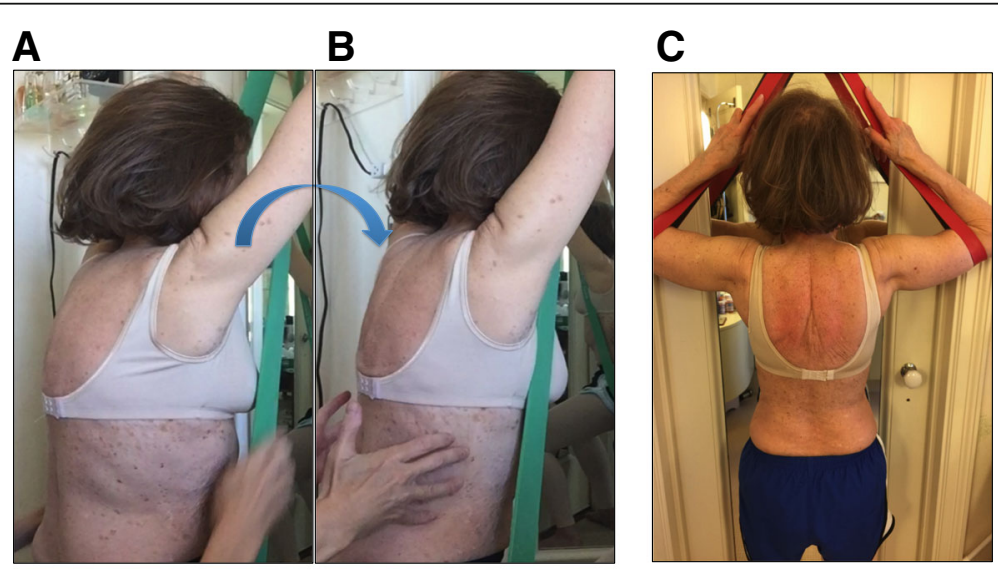

D

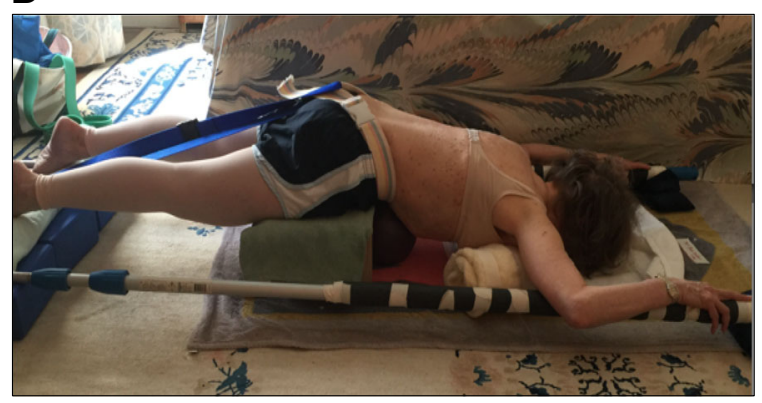

Fig. 3 Sample exercises used by patient. From left to right: a Modified Semi-hanging starting position and $\mathbf{b}$ during the activation; $\mathbf{c}$ Modified "Iguana"; $\mathbf{d}$ Prone on stool with belt traction 


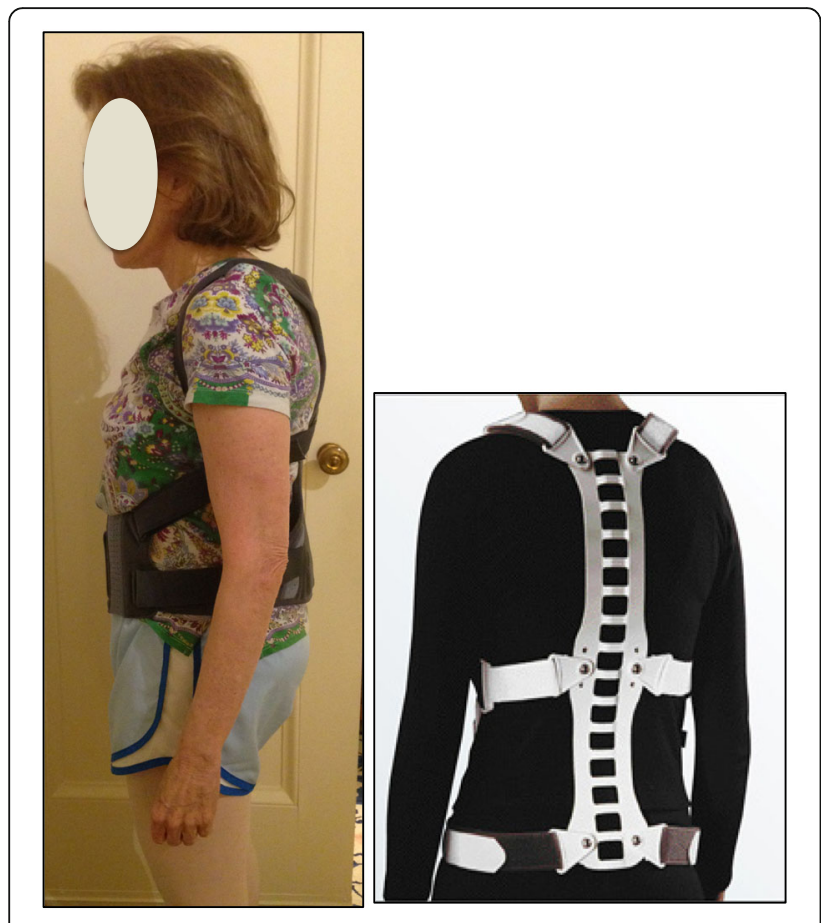

Fig. 4 Patient wearing the SpinoMed brace

orignally designed for patients with a diagnosis of osteoporosis [13]. This brace, like other braces for kyphosis, aims to reduce the axial load and shift the center of gravity [14]. It consists of a rigid moldable support contained in a garment that is worn like a backpack and provides support for the lumbar and the thoracic regions of the spine (see Fig. 4). Multiple positive benefits are reported in the literature regarding bracing alone or bracing and exercises for SK [15-18], including a $73 \%$ increase in back extensor strength, $58 \%$ increase in abdominal flexor strength, $11 \%$ decrease in angle of kyphosis, $25 \%$ decrease in body sway, $7 \%$ increase in vital capacity, $38 \%$ decrease in average pain, $15 \%$ increase in well-being, and $27 \%$ decrease in limitations of daily living [13].

During the period of treatment the patient was monitored daily. On days when the therapist was not present, the patient reported which exercises she performed. All tests and and measurements were repeated 6 months after the evaluation.

\section{Results}

After a six-month treatment period, the patient was re-evaluated. The patient experienced significant and measurable improvement. The thoracic kyphosis Cobb angle was reduced to $70^{\circ}$ and the lumbar lordosis Cobb angle improved to $57^{\circ}$, the lumbar scoliosis curvature decreased to $12^{\circ}$ and L3 (lumbar curve apex) vertebral rotation to 1 (according to the Nash and Moe scale of rotation). A second significant improvement was observed on the patient's recent $x$-ray (taken in October 2015) with thoracic kyphosis measuring $64^{\circ}$ and lumbar lordosis $55^{\circ}$ (Fig. 5). The quality-of-life score showed improvement with a score of 4.5 on the SRS 22. Pain score diminished to 0 . Trunk deviation improved by $2.2 \mathrm{~cm}$. In addition, a change in the patient's scoliosis rotation and Cobb angle was observed as a consequence

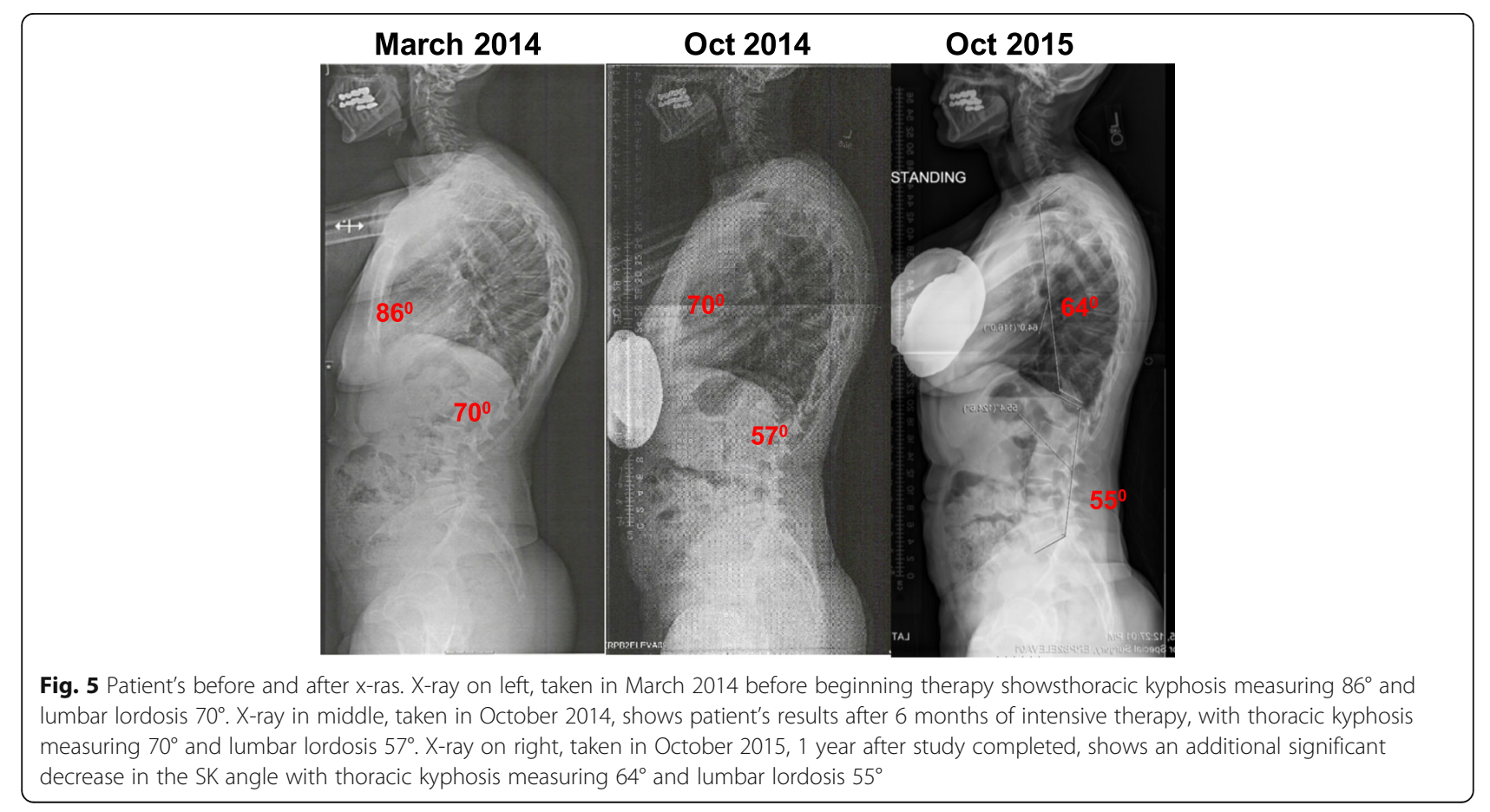


of the exercises. The patient's core and back extensors strength improved to good plus $(+4 / 5)$. She reported that she felt more comfortable with her appearance and was satisfied with the results.

\section{Conclusions}

These findings suggest that intensive PT utilizing the BSPTS/Schroth method and bracing was a successful method of treating this adult patient with SK and that patient compliance with home exercises and brace was an important factor contributing to her results.

\section{Acknowledgments}

I would like to thank the patient for providing detailed information and necessary imaging to complete this case report. I would also like to thank Dr. Manuel Rigo for his support and invaluable contribution to my education.

\section{Declarations}

This article has been published as part of Scoliosis and Spinal Disorders Volume 11 Supplement 2, 2016. Research into Conservative Management of Spinal Deformities: Short Articles from the SOSORT 2015 Meeting. The full contents of the supplement are available online http://scoliosisjournal. biomedcentral.com/articles/supplements/volume-11-supplement-2.

\section{Availability of data and materials}

Data for this case report is given fully in this report and material can be provided upon request from the author.

\section{Author's contributions}

$\mathrm{HB}$ designed the specific and individual exercise program for the patient, carried out the treatment and guided the family on the program. HB also collected and analyzed the data.

\section{Author's information}

Owner of SchrothNYC, New York, NY USA.

\section{Competing interests}

The author declares that he/she has no competing interests.

\section{Consent for publication}

Written informed consent was obtained from the patient for treatment, photos, and publication of this case study. A copy of the written consent is available for review by the Editor of this journal. Written consent was obtained from the patient for publication of this study.

\section{Ethics approval and consent to participate}

Ethics approval not applicable. Written informed consent was obtained from the patients for the publication of their cases and any accompanying images. A copy of the written consent is available for review from the Editor-in-Chief of this journal.

No institutional Review Board needed to approved study. The patient provided informed consent prior to the examinations.

\section{Published: 14 October 2016}

\section{References}

1. Lowe TG, Breton LG. Evidence based medicine: analysis of scheuermann kyphosis. Spine. 2007;32(19):115-9.

2. Katzman WP, Wanek L, Shepherd JA, Sellmeyer DE. Age-related hyperkyphosis: its causes, consequences, and management. J Orthop Sports Phys Ther. 2010;40(6):352-60.

3. lemolo B. Seven criteria to treat Scheuermann's disease. Scoliosis. 2007; 2(suppl1):S39.

4. Mauroy JC, Weiss HR, Aulisa AG, Aulisa L, Brox JI, Durmala J, Fusco C, Grivas TB, Hermus J, Kotwicki T, Le Blay G, Lebel A, Marcotte L, Negrini S, Neuhaus L, Neuhaus T, Pizzetti P, Revzina L, Torres B, Van Loon PJM, Vasiliadis E, Villagrasa M, Werkman M, Wernicka M, Wong MS, Zaina F. 7th SOSORT consensus paper: conservative treatment of idiopathic \& Scheuermann's kyphosis. Scoliosis. 2010;5:9.

5. Weiss HR, Dieckmann J, Gerner HJ. Outcome of in-patent rehabilitation in patients with M. Scheuermann evaluated by surface topography. Stud Health Technol Inform. 2002;88:246-9.

6. Weiss HR, Dieckmann J, Gerner HJ. Effect of intensive rehabilitation on pain in patients with Scheuermann's disease. Topography. Stud Health Technol Inform. 2002:88:254-7.

7. Sinaki M, Itoi E, Rogers JW, Bergstralh EJ, Wahner HW. Correlation of back extensor strength with thoracic kyphosis and lumbar lordosis in estrogendeficient women. Amer J Phys Med Rehab. 1996;75(5):370-5.

8. Ball JM, Cagle P, Johnson BE, Lucasey C, Luker BP. Spinal extension exercises prevent natural progression of kyphosis. Osteoporos Int. 2009;20(3):481-9.

9. Montgomery SP, Erwin WE. Scheuermann's kyphosis- long-term results of milwaukee brace treatment. Spine. 1981;6(1):5-8.

10. Zaina F, Atanasio S, Ferraro C, Fusco C, Negrini A, Romano M, Negrini S. Review of rehabilitation and orthopedic conservative approach to sagittal plane diseases during growth: hyperkyphosis, junctional kyphosis, and scheuermann disease. Eur J Phys Rehabil Med. 2009;45(4):595-603.

11. Nash CL, Moe JH. Astudy of vertebral rotation. J Bone Joint Surg Am. 1969; 51(2):223-9.

12. Rigo M. 3-D Treatment of Scolisois According to the Principles of C.L Schroth: Level 1 Certification Course Manuel. Barcelona Spain; 2015

13. Pfeifer M, Begerow B, Minne HW. Effects of a new spinal orthosis on posture, trunk strength, and quality of life in women with postmenopausal osteoporosis: a randomized trial. Am J Phys Med Rehabil. 2004;83:177-86.

14. White AA, Panjabi MM, Thomas CL. The clinical biomechanics of kyphosis deformities. Clin Orthop. 1977;128:8-17.

15. Lin JT, Lane JM. Nonpharmacologic management of osteoporosis to minimize fracture risk. Nat Clin Pract Rheumatol. 2008;4:20-5.

16. Sinaki M. Can strong back extensors prevent vertebral fractures in women with osteoporosis? Mayo Clin Proc. 1996;71:951-6.

17. Sinaki M, Khosla S, Limburg PJ. Muscle strength in osteoporotic versus normal women. Osteoporos Int. 1993;3.

18. Norton PL, Brown T. The immobilization efficiency of back braces, their effect on the posture and motion of the lumbosacral spine. J Bone Joint Surg Am. 1957;39:111-39.
Submit your next manuscript to BioMed Central and we will help you at every step:

- We accept pre-submission inquiries

- Our selector tool helps you to find the most relevant journal

- We provide round the clock customer support

- Convenient online submission

- Thorough peer review

- Inclusion in PubMed and all major indexing services

- Maximum visibility for your research

Submit your manuscript at www.biomedcentral.com/submit
) Biomed Central 